\title{
Elementos da linguagem fotográfica: uma proposta de categorização
}

\author{
Elements of photographic language: a categorization proposal
}

Ana Leticia Oliveira do Amaral, Berenice Santos Gonçalves

design, linguagem da fotografia, categorização

\begin{abstract}
A fotografia como um meio de comunicação tem como um de seus propósitos otimizar o processo de aquisição da informação, satisfazer as necessidades informacionais dos leitores pretendidos e de promover eficiência comunicativa. Esta se constitui primordial na produção cultural contemporânea, além de ter uma utilização fundamental e extensiva em diferentes áreas do conhecimento. Dessa forma, conhecer e compreender os elementos constitutivos da linguagem da fotografia, permite a definição, planejamento, interpretação e análise de diferentes tipos de imagens. Para tanto, este estudo se propôs a gerar uma classificação dos elementos constitutivos da linguagem fotográfica. Dessa maneira, a categorização proposta neste estudo resultou em dois grandes eixos chamados Dimensão Conceitual e Atributos técnicos, visto que busca elucidar os elementos perenes a qualquer tipo de fotografia dos que estão atrelados aos aparatos tecnológicos. O estudo contribui para uma melhor compreensão da linguagem fotográfica e potencializa o desenvolvimento de competências para a leitura crítica de imagens.
\end{abstract}

design, photographic language, categorization

One of the purposes of the photography, as a means of communication, is to optimize the information acquisition process, satisfy the informational needs of the intended readers, and promote communicative efficiency. Photography is essential in contemporary cultural production, it has a fundamental and extensive use in different areas of knowledge. Thus, knowing and understanding the constituent elements of the photographic language, allows the definition, planning, interpretation, and analysis of different image types. To this end, this study aimed to generate a classification of the constituent elements of the photographic language. Thus, the categorization proposed in this study resulted in two main axes called Conceptual Dimension and Technical Attributes, since it seeks to elucidate the elements perennial to any type of photography of those linked to technological apparatus. The study contributes to a better understanding of the photographic language and enhances the development of skills for critical image reading.

\section{Introdução}

Na sociedade contemporânea, a imagem fotográfica possui uma presença ubíqua, na qual diversos aparatos capturam e compartilham milhões de imagens a todo o momento no mundo (Hand, 2012; Santaella, 2014; Manovich, 2017). As funcionalidades dos equipamentos tecnológicos se unem para potencializar a mobilidade e a interatividade dos conteúdos, mudando as relações sociais, tecnológicas, econômicas e industriais. Além disso, apesar da

Anais do $10^{\circ} \mathrm{CIDI}$ e $10^{\circ} \mathrm{CONGIC}$

Kelli C.A.S. Smythe, Rafael de Castro Andrade (orgs.)

Sociedade Brasileira de Design da Informação - SBDI

Curitiba | Brasil | 2021
Proceedings of the $10^{\text {th }} \mathrm{CIDI}$ and $10^{\text {th }}$ CONGIC

Kelli C.A.S. Smythe, Rafael de Castro Andrade (orgs.)

Sociedade Brasileira de Design da Informação - SBDI Curitiba | Brazil | 2021 
imagem fotográfica ter se tornado trivial na atualidade (Santaella, 2014), ela tem uma utilização fundamental e extensiva no estudo de diversas áreas do conhecimento (Rubinstein, 2009), possui uma estreita relação com as atividades do Design e constitui-se primordial à produção cultural contemporânea.

Guedes (2016) destaca que no decorrer da sua história, a fotografia alterou profundamente as coordenadas de espaço e tempo na comunicação humana. Nesse sentido, Hand (2012) explica que o surgimento da fotografia digital como uma prática comum transformou a paisagem da comunicação visual e da cultura, visto que eventos, atividades, momentos, objetos e pessoas são "capturados" e "distribuídos" como imagens em uma escala sem precedentes. Contudo, apesar da tecnologia digital ter transformado a forma de armazenar, veicular e até mesmo a forma de capturar imagens, a fotografia ainda está atrelada ao conhecimento e à aplicação de princípios herdados do processo analógico que auxiliam na definição, planejamento, configuração do conteúdo e análise de imagens fotográficas.

Dessa maneira, a linguagem fotográfica está fortemente relacionada a área do design da informação, pois a fotografia como um meio de comunicação tem como um de seus propósitos otimizar o processo de aquisição da informação, satisfazer as necessidades informacionais dos leitores pretendidos e de promover eficiência comunicativa.

Diante ao exposto, compreender a linguagem da fotografia é fundamental para potencializar o letramento imagético e midiático, principalmente na formação de profissionais, como designers, que utilizam a fotografia como um recurso constante. Como afirma Arlindo Machado (2000), a fotografia é a base ideológica, conceitual e tecnológica de boa parte das mídias contemporâneas e, dessa forma, ao compreendê-la e defini-la é possível compreender as estratégias semióticas, os modelos de construção e percepção e as estruturas de sustentação de toda a produção contemporânea de signos visuais e auditivos.

Assim, considerando o exposto e, buscando orientar os profissionais que utilizam a linguagem da fotografia, este estudo tem por objetivo analisar as abordagens de quatro autores que elencaram os elementos pertencentes à linguagem da fotografia e, com base na comparação entre as abordagens, em um esforço inicial, propor uma categorização dos elementos da linguagem fotográfica, a partir de uma perspectiva hierárquica e conceitual. Para tanto, a primeira parte deste artigo resgata os conceitos da linguagem da fotografia. Na segunda parte, realizou-se um levantamento bibliográfico para a identificação dos autores e, posteriormente, efetivou-se uma análise e sistematização que possibilitou a identificação dos elementos que foram utilizados para a categorização proposta. Em seguida, os resultados são explicitados.

\section{A linguagem da fotografia}

Genericamente entende-se por linguagem um sistema de comunicação ou de expressão formado por um conjunto de signos convencionados combinados entre si por meio de códigos ou normas (Sardina, 1995). Conforme Acaso (2009, p.25), "a linguagem visual é o código específico da comunicação visual; é um sistema com o qual podemos enunciar mensagens e 
receber informações através do sentido da visão". Com isso, Sobral (2001) afirma que perceber a imagem fotográfica como linguagem é solidificar a base para sua leitura crítica e ao mesmo tempo desenvolver a consciência da responsabilidade que a imagem fotográfica exerce na educação da sociedade.

Manovich (2017) argumenta que a cultura de imagens que se desenvolve em torno da mídia tecnológica, além de ser definida pela tecnologia vigente, também é definida por linguagens culturais, ou seja, sistemas de convenções e técnicas que definem assuntos, narrativas, composição, iluminação entre outras características da imagem. Para o autor, uma linguagem visual representa escolhas sistemáticas feitas em todas as dimensões visuais reconhecidas como relevantes para criadores e públicos.

Nesse sentido, compreender a linguagem da fotografia é fundamental para potencializar a alfabetização visual. Tubío (2012) ressalta que a aprendizagem visual deve incluir o desenvolvimento de competências para análise crítica e compreensão de objetos visuais, assim como competências para o tratamento de técnicas específicas em função da criação de objetos visuais para comunicação.

Por vezes concebe-se a criação de imagens fotográficas como algo automático, como se ao acionar a câmera, tudo já estivesse programado, sendo preciso somente pressionar o botão. No entanto, é necessário refletir sobre a imagem fotográfica, para que se possa entender, criar e comunicar. Sem compreensão da linguagem visual e noção da linguagem fotográfica, as pessoas produzem e recebem qualquer imagem, sem uma análise crítica. Assim, o profissional faz escolhas ao criar, editar e produzir imagens fotográficas. Essas escolhas consideram os elementos da fotografia que estão relacionados às características como foco, a composição da imagem e ao que o fotógrafo pretende comunicar (Way, 2006). Dessa maneira, as imagens resultantes possuem diversos significados dependendo de como elas são interpretadas.

Além disso, cabe mencionar que a fotografia, tanto sua criação quanto sua leitura, estão condicionadas ao processo de interpretação de imagens particular, ou seja, é diretamente relacionada a quem a faz (fotógrafos, designers, artistas, usuários amadores, etc.). Contudo, este estudo traz um esforço em mapear para além das subjetividades, mesmo que de modo incipiente, a organização dos elementos essenciais a linguagem fotográfica.

\section{Procedimentos metodológicos}

Frente a fotografia ubíqua difundida na sociedade atual, resgata-se a afirmativa de Belt (2008) ao tratar da transição entre a fotografia analógica para a digital. A autora salienta ser imperativo lembrar os elementos sobre os quais o próprio meio se baseia, ressaltar o funcionamento e os resultados desses elementos e eliminar a barreira percebida entre uma mídia e outra. A fim de categorizar estes elementos e proporcionar uma forma, mesmo que inicial, de orientação aos profissionais quanto a linguagem fotográfica, resgatou-se pesquisas que buscaram elencar e dividir de diferentes formas os fundamentos constitutivos da linguagem fotográfica. 
Segundo Bardin (2016, p. 147) "a categorização é uma operação de classificação de elementos constitutivos de um conjunto por diferenciação e, em seguida por reagrupamento segundo o gênero, com os critérios previamente definidos". O processo de categorização requer pensar o domínio de forma dedutiva, ou seja, determinar as classes de maior abrangência dentro de uma determinada temática (Campos \& Gomes, 2007). Classificar os elementos em categorias estabelece a investigação do que cada um deles tem em comum com os demais. Sendo assim, a investigação foi estruturada em quatro principais etapas:

1. Revisão de literatura tradicional e síntese dos autores selecionados;

2. Análise e sistematização das abordagens;

3. Construção das categorias a partir de uma perspectiva hierárquica e conceitual.

\section{Revisão de literatura tradicional e síntese dos autores selecionados}

A seleção dos autores para a análise levou em consideração a recorrência de citações dos autores em estudos da área de fotografia previamente consultados em uma revisão bibliográfica tradicional (RBT) de caráter amplo e exploratório utilizada para a definição do aporte teórico de uma pesquisa de mestrado (Amaral, 2019). De acordo com Provanov e Freitas (2013) a RBT busca identificar e expor abordagens existentes em publicações consolidadas sobre $o$ assunto.

A seguir serão apresentadas as abordagens dos autores quanto aos fundamentos constitutivos da linguagem fotográfica. Após uma ampla busca, os autores supracitados, foram escolhidos para este estudo, visto que, além da recorrência de citações em estudos da área também apresentam uma fundamentação consistente e estruturada sobre a linguagem fotográfica. Visando uma melhor caracterização de cada elemento, também se buscou informações complementares que as autoras consideram pertinentes à temática. Desse modo, os autores selecionados foram: Milton Guran (1992), Cynthia Way (2006), Angela Faris Belt (2008) e Michael Freeman (2012; 2015).

\section{Classificação de Milton Guran}

Milton Guran (1992), em seu livro "Linguagem fotográfica e informação", afirma que o ato de fotografar se realiza em uma fração mínima de tempo que captura e traduz plasticamente uma cena. Também menciona que a composição fotográfica é resultado da harmonização de fatores de ordem técnica e de conteúdo, constituindo o pleno exercício da linguagem fotográfica. Assim, para o autor, os elementos relacionados à linguagem em questão podem ser agrupados dentro do tópico composição, sendo ele dividido em:

- enquadramento: é tratado como a organização, no visor da câmera, de todos os elementos geométricos que formam a realidade da cena, dispondo-os de forma a evidenciá-la com clareza e objetividade. Guran (1992) ressalta que a única regra definitiva de enquadramento é a "limpeza" da imagem no que toca à informação principal, salvo casos em que a informação principal for a confusão ou desorganização. 
Além disso, o autor afirma que um bom enquadramento é "resultado da capacidade do fotógrafo em perceber geometricamente a realidade, trabalhando a dinâmica das superfícies, massas e linhas" (Guran, 1992, p. 27).

- luz: é o elemento que dá volume e profundidade a imagem, assim como sua intensidade, tipo e direção são fatores determinantes para o resultado de uma fotografia.

- foco, diafragma e velocidade: são ajustes operacionais da câmera que impactam diretamente no conteúdo da mensagem que a imagem quer passar. A quantidade de luz que chega até a superfície fotossensível é regulada pelo diafragma da lente e pela velocidade de obturação. $O$ foco é o ajuste feito para conferir nitidez a uma fotografia por completo ou em determinados planos.

- a atuação das objetivas: Guran (1992) destaca que cada objetiva (lente) tem sua forma particular de reproduzir a realidade. Por isso, a escolha da objetiva depende de quais aspectos o fotógrafo busca abordar na cena capturada. Sendo as lentes mais usuais, a normal, a grande angular, tele e a macro .

- filme, revelação e cópia: apesar de não serem características recorrentes nos dias atuais, na fotografia tradicional esses três componentes constituiam a parte química do processo de fotografar. $\mathrm{O}$ autor afirma que quatro características dos filmes (películas), combinadas com a ação dos reveladores, são fatores que influenciam na linguagem fotográfica, a saber, a sensibilidade (capacidade de registrar a luz), a acutância (capacidade de registar detalhes), o contraste (diferença entre áreas mais e menos iluminadas) e a granulação (o tamanho e a forma do grão).

- o momento: é uma fatia muito rápida da realidade, por isso escolher o momento só é possivel a partir do envolvimento do fotógrafo com a cena que está se organizando sob o visor da câmera.

Ainda que seja uma referência de certa forma antiga, muitos dos princípios tratados por Guran (1992) na fotografia tradicional (analógica) ainda são imprescindíveis para a fotografia mediada por aparatos digitais.

Quadro 1: Síntese de Guran.

\begin{tabular}{ll}
\hline Divisão & Fundamentos constituintes \\
\hline Composição & Enquadramento \\
& Luz \\
& Foco, diafragma e velocidade \\
& Objetivas \\
Filmes, resolução e cópia & Sensibilidade (ISO) \\
& - Acutância \\
& - Contraste \\
& - Granulação \\
Momento & \\
\hline
\end{tabular}




\section{Abordagem de Angela Faris Belt}

De acordo com Angela Faris Belt (2008), o fundamento técnico da gramática da linguagem fotográfica é formado por quatro elementos que são inerentes a cada imagem criada pela ação da luz. E devem ser abordados habilmente pelos profissionais, independente da escolha da mídia e do uso final das imagens. Para Belt (2008) qualquer prática de fotografia que não aborda conscientemente os elementos gramaticais da linguagem fotográfica não consegue maximizar seu potencial.

A autora também ressalta que esses conceitos foram construídos com base no processo de criação de imagens fotográficas bidimensionais. Entretanto, podem e devem ser aplicados de forma mais ampla para abordar questões relacionadas a fotografias usadas em holografia, multimídia, instalações, aplicações tridimensionais e inúmeras outras. Dessa maneira, os elementos são divididos em quatro grupos, abordados nos parágrafos a seguir.

O enquadramento fotográfico e suas bordas é definido por Belt (2008) como uma estrutura que circunscreve as decisões do fotógrafo em relação ao conteúdo da imagem. Para a organização visual e a hierarquização do conteúdo dentro do enquadramento a autora aponta a existência de três importantes aspectos, a saber, o ponto de vista (diz respeito a distância e a posição da câmera em relação ao assunto), a justaposição (é o relacionamento e a interação entre conteúdos da imagem) e os planos (que determinam o ritmo de leitura e são divididos em três tipos: paralelo, diagonal e sobreposto). Além disso, neste elemento é tratado o espaço de transição entre a imagem e seus arredores, ou seja, a significância das bordas, que para Belt (2008) são comparadas a impressão causada pela capa de um livro antes de conhecer a sua história.

O segundo elemento apresentado é nominado foco, e enquadra os seguintes aspectos: abertura, lentes e profundidade de campo. Nesta divisão a abertura é dissociada da lente, pois segundo a autora, uma lente não é necessária para criar imagens a partir da luz. Contudo, no que diz respeito às câmeras, a abertura (também chamada $f$-stop) é responsável pela quantidade de luz que entra pela lente. A profundidade de campo "descreve a relação de primeiro plano com o plano de fundo, definindo o que de uma imagem estará em foco" (Belt, 2008, p. 110, tradução nossa). Para o item lentes, primeiro são tratadas as câmeras sem lentes, como a câmara obscura e a câmera pinhole e posteriormente são mencionadas as objetivas e suas características.

A velocidade do obturador e seus efeitos em relação ao tempo e ao movimento constituem o terceiro grupo. Esse elemento controla o período de tempo que o dispositivo fotossensivel recebe a exposição da luz. Para Belt (2008) a interrelação dos fatores velocidade do obturador, a natureza estática do meio e o movimento na frente da câmera ou da própria câmera são responsáveis pelo movimento gravado em uma fotografia. Em relação ao tempo, a autora afirma que pode ser traduzido de quatro formas diferentes para a fotografia, a saber, congelado, borrado, estático ou sobreposto.

Por fim, como quarto elemento é apresentado os materiais e processos físicos que compõem e contribuem significativamente para o modo de construção da imagem. Que para 
Belt (2008) dizem respeito ao ISO, resolução e acutância, além dos métodos utilizados para impressão de imagens fotográficas. A autora ainda afirma que esses elementos não operam de forma hierárquica ou sequencial, cada um deles desempenha um papel único.

Quadro 2: Síntese de Belt.

\begin{tabular}{|c|c|}
\hline Divisão & Fundamentos constituintes \\
\hline Enquadramento e & Ponto de vista \\
\hline \multirow[t]{6}{*}{ Bordas } & Justaposição \\
\hline & Planos \\
\hline & - Diagonal \\
\hline & - Paralelo \\
\hline & - Sobreposto \\
\hline & Bordas \\
\hline \multirow[t]{3}{*}{ Foco } & Abertura \\
\hline & Lentes \\
\hline & Profundidade de campo \\
\hline \multirow[t]{6}{*}{ Velocidade do Obturador } & Tempo \\
\hline & - Congelado \\
\hline & - Parado \\
\hline & - Estático \\
\hline & - Sobreposto \\
\hline & Movimento \\
\hline \multirow[t]{3}{*}{ Materiais e Processos } & ISO \\
\hline & Resolução \\
\hline & Acutância \\
\hline
\end{tabular}

\section{Abordagem de Cynthia Way}

Já para Cynthia Way (2006) a linguagem da fotografia se distingue das outras linguagens visuais por seus dois aspectos essenciais: a luz e a câmera. Visto que para a autora, as considerações técnicas, como escolhas de iluminação e tipo de câmera, determinam o aspecto final da imagem. Além disso, os fotógrafos fazem escolhas artísticas que consideram os elementos da fotografia ao criar, editar e produzir suas imagens.

Dessa forma, a autora apresenta os elementos considerados essenciais para a linguagem fotográfica arranjados em cinco categorias, sendo elas, (1) atributos fotográficos que engloba os elementos da luz, o foco, o tempo, o movimento, o ponto de vista, o enquadramento, o corte e a técnica; (2) composição composta por forma, linha, ângulo, cor e tom, textura, profundidade e composição geral; (3) conteúdo que trata do sujeito, do plano de fundo, do primeiro plano, das pessoas, da história, do humor/sentimento e do símbolo/metáfora; (4) estilo e gênero e, por fim (5) significado que diz respeito a intenção/propósito do fotógrafo e o significado pretendido. 
Quadro 3: Síntese de Way.

\begin{tabular}{|c|c|}
\hline Divisão & Fundamentos constituintes \\
\hline \multirow[t]{8}{*}{ Atributos Fotográficos } & Luz \\
\hline & Foco \\
\hline & Tempo \\
\hline & Movimento \\
\hline & Ponto de vista \\
\hline & Enquadramento \\
\hline & Corte \\
\hline & Técnica \\
\hline \multirow[t]{7}{*}{ Composição } & Forma \\
\hline & Linha \\
\hline & Ângulo \\
\hline & Cor e tom \\
\hline & Textura \\
\hline & Profundidade \\
\hline & Composição geral \\
\hline \multirow[t]{7}{*}{ Conteúdo } & Sujeito \\
\hline & Plano de fundo \\
\hline & Primeiro plano \\
\hline & Pessoas \\
\hline & História \\
\hline & Humor/sentimento \\
\hline & Símbolo/metáfora \\
\hline \multirow[t]{2}{*}{ Estilo e Gênero } & Estilo \\
\hline & Gênero \\
\hline Significado & Significado \\
\hline
\end{tabular}

\section{Princípios fundamentais de Michael Freeman}

Michael Freeman $(2012 ; 2015)$ tem o propósito de ensinar os princípios fundamentais da fotografia. Com base nas suas publicações é possivel destacar a divisão dos elementos em três grandes grupos, sendo eles, a composição, a exposição e a luz e iluminação. Para Freeman (2012) compreender esses fundamentos trata-se, além de desenvolver o senso artístico do fotógrafo, de potencializar a capacidade de comunicar ideias por meio da fotografia. A composição passa por quase todos os elementos das imagens e divide-se em cinco: (1) fundamentos (que engloba a escolha do assunto, preenchimento do quadro, escolha da profundidade de campo e as linhas horizontais e verticais), (2) geometria (trata sobre o posicionamento do assunto, das linhas de atenção verticais e diagonais, do equilíbrio e simetria assim como a razão áurea), (3) cor, padrão, espaço e luz, (4) técnica (que é abordada por Freeman (2012) como a distância focal e os tipos de objetivas) e a (5) pós-produção.

A exposição faz referência à quantidade de luz que é capturada durante o clique, com o ajuste de três controles de câmera, o ISO (que é uma referência à sensibilidade do filme à luz), a 
abertura das lentes e a velocidade do obturador (Freeman, 2015). Este elemento é dividido em três: os fundamentos, a medição da luz e os métodos de exposição avançados.

No grupo luz e iluminação destaca-se os fundamentos da iluminação e os seus tipos como a luz do dia, luz artificial, iluminação de estúdio e os estilos. É possível perceber que Freeman $(2012 ; 2015)$ trabalha alguns tópicos em mais de um elemento, visto que para o autor todas as partes da linguagem fotográfica estão interligadas.

Quadro 4: Síntese de Freeman.

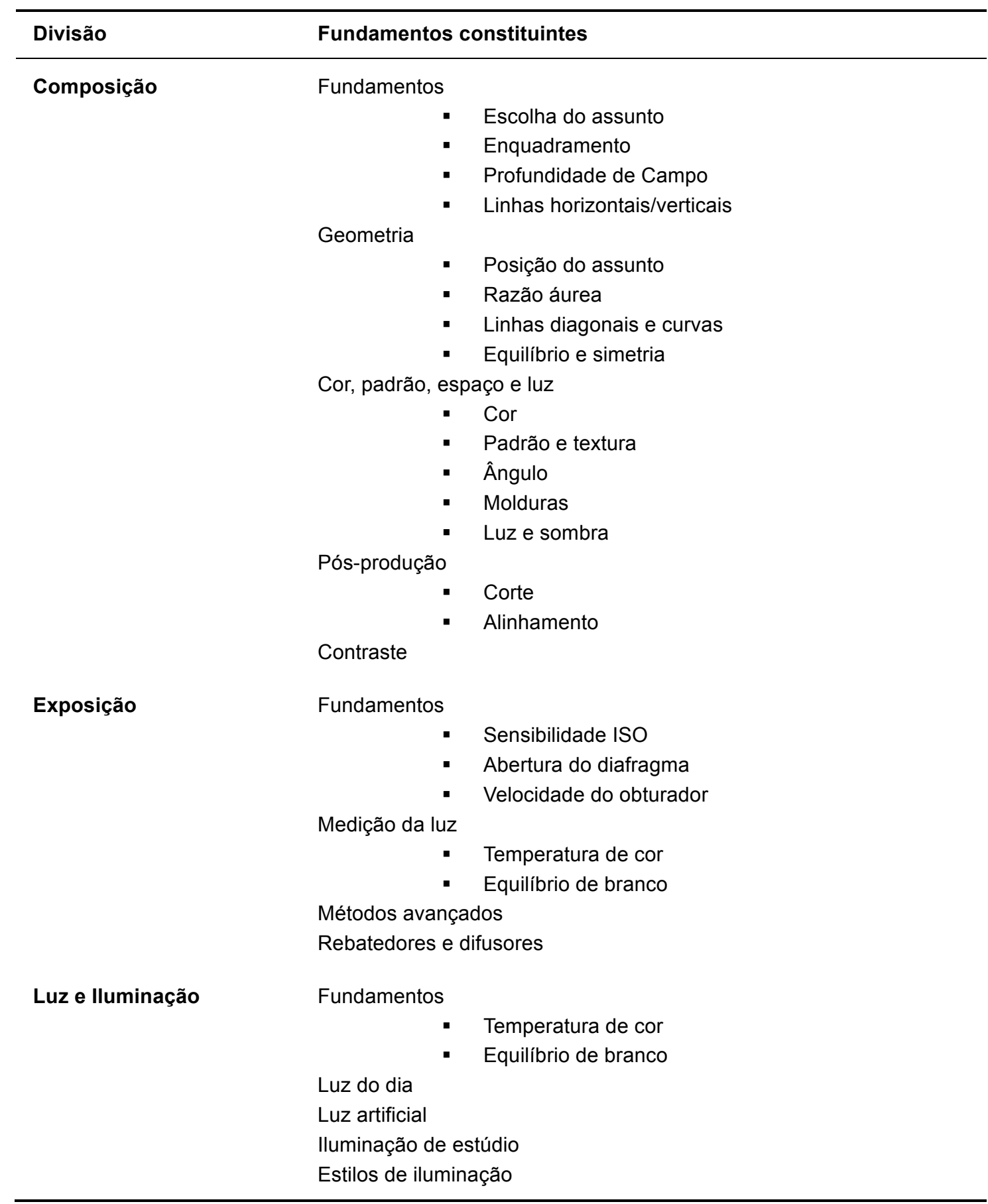


Com base nessa breve revisão é possível perceber que o arranjo dos elementos varia de um autor para outro, não havendo um consenso na divisão e classificação dos princípios que compõem a linguagem da fotografia. Além disso, ao se fazer uma rápida busca na internet, sobre os elementos dessa linguagem, se encontra um expressivo número de publicações que apresentam diferentes classificações construídas a partir da experiência de profissionais da área. Contudo, frente a expressiva participação fotográfica no cotidiano das pessoas, o número de investigações encontradas em revistas científicas acerca da fotografia, e sobre sua linguagem ainda são ínfimas.

\section{Análise e sistematização das abordagens}

Apesar da organização dos elementos variar de um autor para outro, ao analisar as contribuições identifica-se pontos em comum, como o enquadramento, a luz, o foco, a abertura do diafragma, a velocidade do obturador e sensibilidade de ISO, entre outros. Assim, a figura 1 permite visualizar a hierarquia e a recorrência dos termos nas abordagens propostas pelos autores.

O elemento "enquadramento", destacado em cinza escuro, se repete nos quatro autores. A luz está apenas em três das abordagens como um elemento independente, no estudo desenvolvido por Belt (2008) esse fundamento aparece diluído no conteúdo apresentado nos outros grupos. Dessa maneira, no comparativo, a cor cinza médio destaca os elementos encontrados em três das propostas, sendo eles, a luz, o foco, a abertura do diafragma, a velocidade do obturador, a sensibilidade ISO e a profundidade de campo. E os elementos realçados em cinza claro são recorrentes em apenas dois autores, como o movimento que aparece nas abordagens de Way (2006) e Belt (2008). 
Figura 1: Comparação das divisões dos fundamentos da linguagem da fotografia.

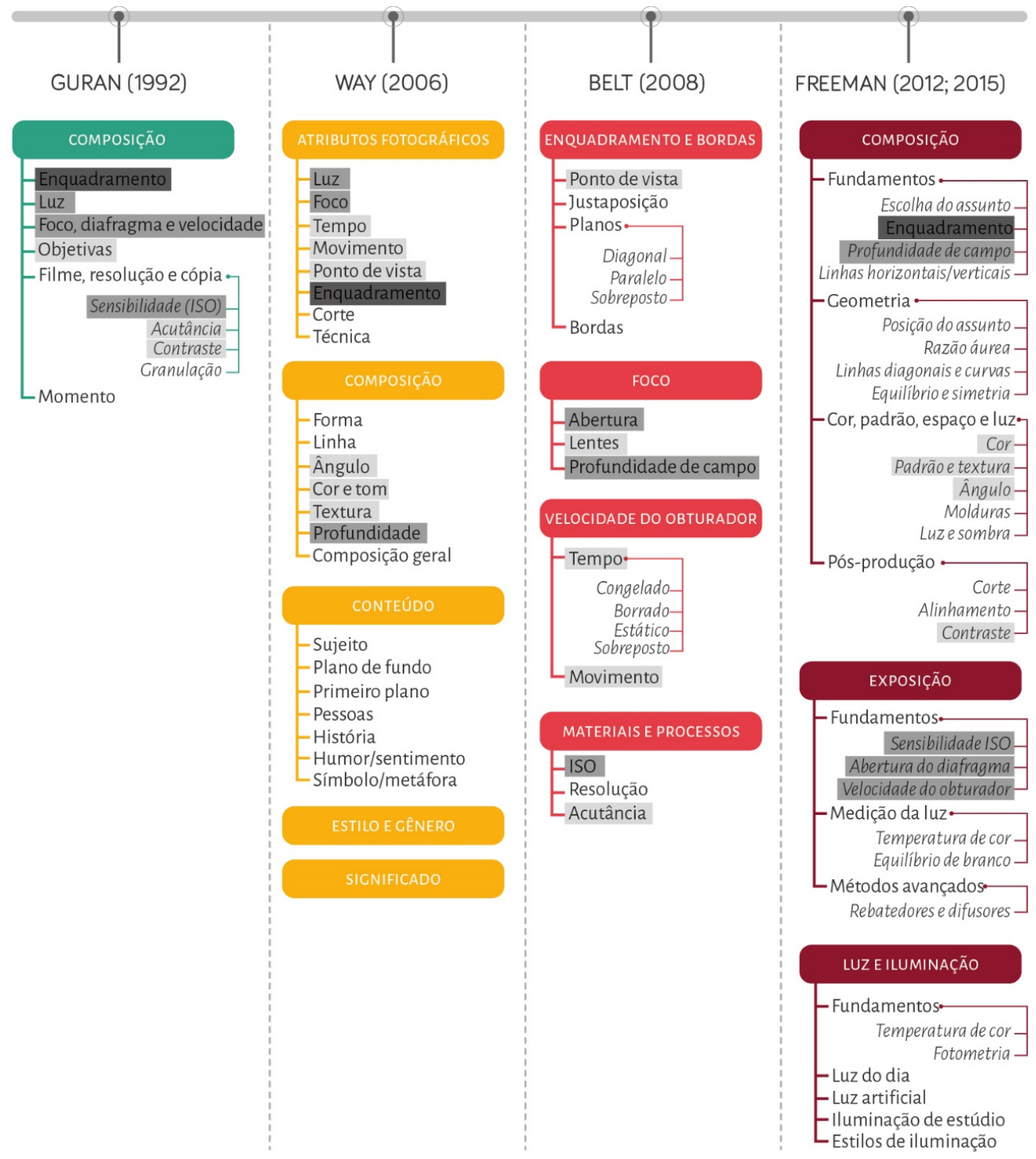

Além disso, ao analisar ou produzir uma imagem é possível identificar uma série de variáveis que dão sentido a ela, essas variáveis podem ser chamadas de princípios da linguagem. Durante o processo de revisão bibliográfica identificou-se diferentes nomenclaturas que definem o conjunto de fundamentos pertencentes a linguagem fotográfica. Assim, para este estudo optou-se pela adoção do termo elementos ${ }^{1}$. Dessa forma, para alcançar uma imagem rica em informações, é necessário compreender que a linguagem fotográfica é regida por um conjunto de elementos que funcionam como princípios.

Deste modo, ao averiguar as abordagens dos autores selecionados nota-se que os elementos são alocados em diferentes classificações, por exemplo, o enquadramento para Guran (1992), Way (2006) e Freeman $(2012 ; 2015)$ faz parte da categoria Composição, já para Belt (2008) o enquadramento é a própria categoria. Além disso, na classificação de Freeman

\footnotetext{
${ }^{1}$ Segundo o dicionário Michaelis (2015) é cada uma das partes integrantes e fundamentais de um todo.
} 
(2012; 2015) há características específicas do elemento luz distribuídas nos três grupos (Composição, Exposição e Luz e iluminação). Quanto a isso, Bardin (2016) afirma que um bom conjunto de categorias deve seguir a condição de exclusão mútua, ou seja, um elemento não pode existir em mais de uma divisão.

Assim, como a categorização é um processo estruturalista² ${ }^{2}$, para a proposição da classificação, primeiramente os elementos foram isolados. Posteriormente, buscou-se agrupálos conforme recorrência e similaridade para, então procurar definir uma organização coesa para o arranjo do conjunto de elementos que formam cada categoria.

\section{Construção das categorias a partir de uma perspectiva hierárquica e conceitual}

Com base na comparação das abordagens dos elementos da linguagem da fotografia dos autores definidos e considerando as recomendações de Bardin (2016) quanto a forma de construção de boas categorias, identificou-se pontos em comum entres os autores e elementos essenciais à produção e leitura de imagens fotográficas, destacados na figura 2.

Figura 2: Proposta de categorização dos elementos da linguagem fotográfica.

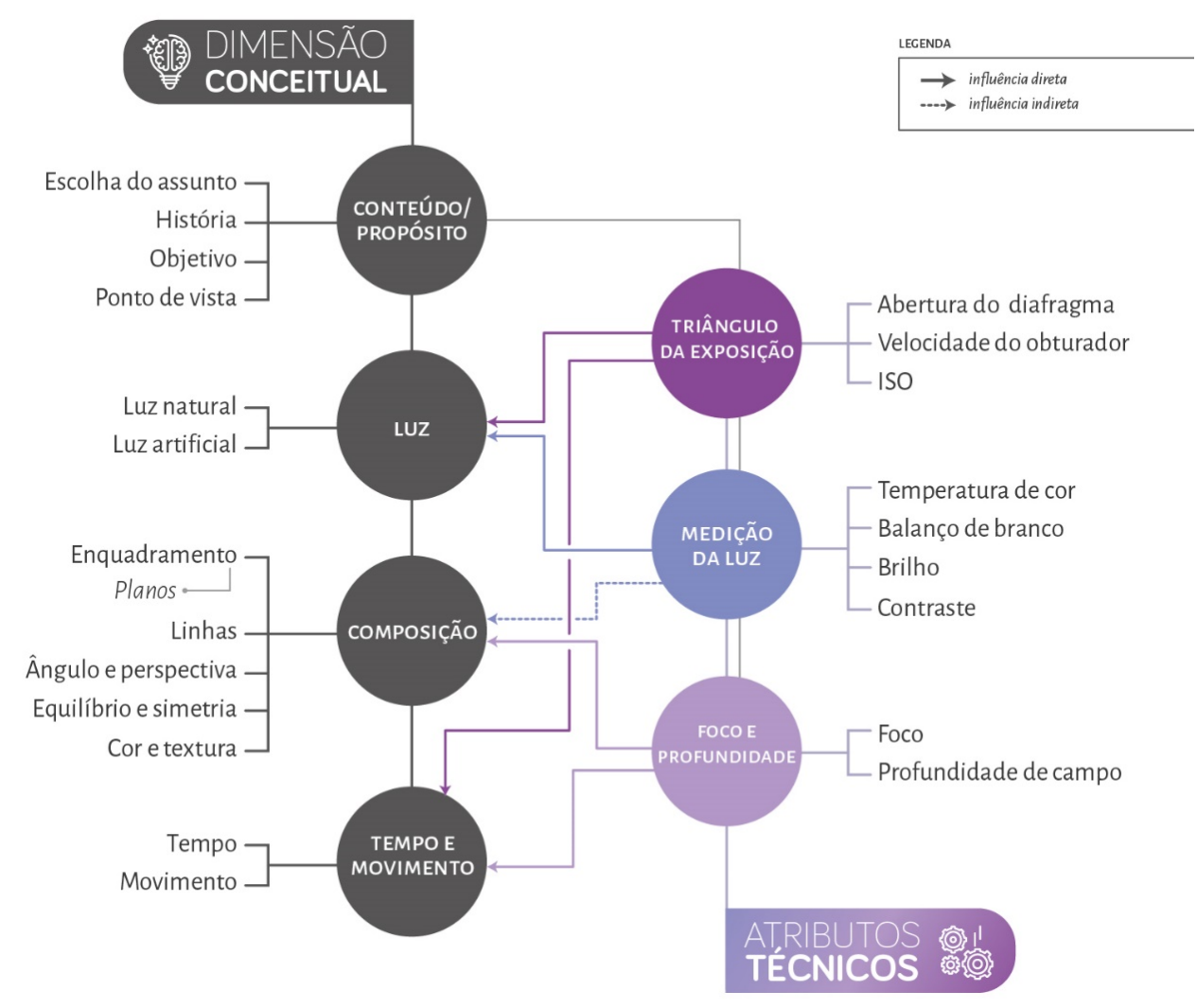

A fim de melhor orientar os profissionais que farão uso da linguagem fotográfica, tanto para produção quanto para leitura de imagens, assim como considerando as especificidades de

\footnotetext{
${ }^{2}$ Para Bardin (2016) esse processo comporta duas etapas: o inventário (isolar os elementos) e a classificação (repartir os elementos e procurar uma certa organização.
} 
formação das diferentes áreas do Design, seja gráfico ou de produto os elementos propostos por Guran (1992), Belt (2008), Way (2006) e Freeman (2012; 2015) foram rearranjados e unificados. Os fundamentos foram reagrupados em dois grandes eixos: Dimensão Conceitual e Atributos Técnicos ${ }^{3}$, de modo a configurarem uma categorização mais perene quanto as mudanças tecnológicas. Ressalta-se que apesar dos elementos terem sido organizados por meio de uma perspectiva hierárquica e conceitual, eles não operam de maneira sequencial, na prática eles se unem na criação da imagem de modo iterativo.

\section{Dimensão Conceitual}

Esse eixo trata dos princípios gerais e particulares da imagem que fazem com que ela seja considerada uma fotografia com características, sintaxe e gramática próprias, ou seja, são os aspectos que pouco dependem do aparato tecnológico utilizado e se repete para todas as imagens criadas a partir da luz. Dessa maneira, essa dimensão engloba as categorias:

- Conteúdo/propósito: está relacionada a forma de comunicar uma mensagem. O ponto de vista trata-se da postura do fotógrafo em relação à percepção e perante o assunto a ser fotografado.

- Luz: é o elemento determinante da fotografia. Compreender o comportamento da luz e as melhores maneiras de explorá-la é primordial à habilidade dos profissionais de produzir imagens de qualidade.

- Composição: é crucial para a solução dos problemas visuais, pois determina o objetivo e o significado da manifestação visual, além de implicar diretamente no que é recebido pelo usuário.

- Tempo e movimento: todas as imagens delineiam o tempo das seguintes formas: congelado, embaçado, estático ou sobreposto (Belt, 2008).

\section{Atributos Técnicos}

Os atributos técnicos são elementos que estão, de certa forma, mais próximos aos aparatos tecnológicos, pois a maioria é composta por ajustes que podem ser aplicados no artefato utilizado. Além disso, pode dizer que os elementos que compõem esse eixo são necessários para alcançar a dimensão conceitual com êxito. Os atributos ajudam a determinar a forma que a imagem é lida. Assim, essa dimensão engloba as categorias:

- Triângulo da exposição: faz referência à quantidade de luz que é capturada durante o clique, com o ajuste de três variáveis, a saber, o ISO (que é uma referência à sensibilidade do filme à luz), a abertura do diafragma das lentes e a velocidade do obturador.

\footnotetext{
${ }^{3}$ Devido ao tamanho limitado deste artigo não é possível apresentar todo o detalhamento das dimensões e de seus elementos, para tanto acesse a página 43 do documento no link: http://www.bu.ufsc.br/teses/PGDE0175-D.pdf.
} 
- Medição da luz: para este estudo a medição da luz foi divida em quatro elementos, sendo eles, temperatura de cor, balanço de branco, brilho e contraste.

- Foco e profundidade: o foco está diretamente relacionado com o centro de atenção da imagem e a profundidade de campo descreve até que ponto objetos que estão mais ou menos perto do plano de foco aparentam estar nítidos, além disso auxilia na construção do significado da imagem registrada.

Percebe-se que cada componente da linguagem fotográfica apresentado agrega uma variedade de sentidos e expressões que, quando combinados de modo consciente, viabilizam ao profissional uma gama de possibilidades para a construção da mensagem pretendida. Além disso, muitos avanços tecnológicos estão direcionados ao ato "pós-fotográfico", ou seja, ao tratamento digital das imagens, relegando e esquecendo fundamentos de linguagem que são inerentes a fotografia tanto digital quanto analógica. Dessa forma, considerando que o designer, enquanto profissional, é um construtor de discursos e atua como um intermediador em processos comunicacionais, essa categorização contribui para uma melhor compreensão da linguagem fotográfica e potencializa o desenvolvimento de competências para a leitura crítica de imagens.

\section{Considerações finais}

A popularização dos aparatos tecnológicos e a simplificação de procedimentos fotográficos têm proporcionado, a um grande número de pessoas, a utilização da fotografia como um meio de expressão. Na área do Design, a fotografia atravessa diversas atividades desde concepção, desenvolvimento e documentação de projetos, e sua utilização está condicionada a escolha de quais elementos da linguagem fotográfica melhor se adequam ao processo de transmissão da informação desejada. Dessa maneira, este estudo buscou categorizar os elementos da linguagem fotográfica, por meio de uma análise comparativa, visando orientar os profissionais que se utilizam dessa linguagem. Pontua-se a importância desse tipo de categorização realizada para o design da informação, pois permite uma organização mais eficaz dos elementos da linguagem fotográfica. Além disso a categorização pode orientar pesquisas de análises, aplicações fotográficas, bem como auxilia na análise de outras mídias que, de certa forma, utilizam a linguagem fotográfica como base de suas próprias linguagens.

Durante o desenvolvimento desta pesquisa, ao buscar autores para a análise, foi possível perceber que não há uma classificação padrão quanto a divisão dos princípios da linguagem fotográfica. Entretanto, alguns elementos são recorrentes nas quatro abordagens consultadas. Dessa forma, a categorização proposta busca contribuir para a potencialização da produção e da leitura crítica de imagens, principalmente na formação de Designers que utilizam a fotografia como um recurso constante. Sugere-se, para estudos futuros a ampliação da análise visando contemplar mais autores, tornando a categorização mais robusta. 


\section{Referências}

Acaso, M. (2009). El lenguaje visual. Barcelona: Paidós.

Amaral, A. L. O. (2019). Fotografia e tecnologias digitais de informação e comunicação:um modelo blended learning direcionado a cursos de Design. [Dissertação de mestrado]. Centro de Comunicação e Expressão. UFSC, Florianópolis.

Bardin, L. (2016). Análise do conteúdo. São Paulo: Edições 70.

Belt, A. (2008). The Elements of Photography: Understanding and Creating Sophisticated Images. Burlington: Focal Press.

Freeman, M. (2012). Composición. Barcelona: Blume.

Freeman, M. (2015). Luz e iluminação. Porto Alegre: Bookman.

Guedes, A. (2016). Re-Visão dos Aspectos de Linguagem da Escritura Fotográfica da Ambiência Digital. [Tese de doutorado]. Centro de Educação, Filosofia e Tecnologia, Universidade Presbiteriana Mackenzie, São Paulo.

Guran, M. (1992). Linguagem fotográfica e informação. Rio Fundo Editora.

Hand, M. (2012). Ubiquitous photography. Cambridge: Polity Press.

Machado, A. (2000). A fotografia como expressão do conceito. Studium, Unicamp. http://www.studium.iar.unicamp.br/dois/1.htm

Manovich, L. (2017). Instagram and Contemporary Image. http://manovich.net/content/04projects/144-instagram-and-contemporary-image/instagram_book_manovich.pdf

Michaelis Dicionário Brasileiro da Língua Portuguesa. (2015). São Paulo: Editora Melhoramentos Ltda.

Rubinstein, D. (2009). Towards Photographic Education. Photographies, 2(2), 135-142. https://www.academia.edu/528410/Towards_Photographic_Education.

Santaella, L. (2014). Linguagens líquidas na era da mobilidade. São Paulo: Paulus.

Sobral, J. (2001). A Importância da Fotografia como Linguagem na Educação.[Dissertação de mestrado]. Fundação Universitária da Região de Blumenau, FURB, Blumenau.

Tubío, D. (2012). Reflexiones sobre la educación visual. Centro de Estudios En Diseño y Comunicación, 39(12), 131-143.

http://fido.palermo.edu/servicios_dyc/publicacionesdc/archivos/346_libro.pdf.

Way, C. (2006). Focus on Photography: A Curriculum Guide. Nova York: International Center of Photography.

\section{Sobre o(a/s) autor(a/es)}

Ana Leticia Oliveira do Amaral, Ma., UFSC, Brasil <amaral.analeticia@gmail.com> Berenice Santos Gonçalves, Dra., UFSC, Brasil < berenice@cce.ufsc.br > 